\title{
Functional mitral stenosis after mitral valve repair is a true anatomic problem that originates from the time of surgery
}

\author{
Vincent Chan, MD, MPH, ${ }^{a, b}$ and Thierry G. Mesana, MD, $\mathrm{PhD}^{\mathrm{a}}$
}

\footnotetext{
From the a University of Ottawa Heart Institute, Ottawa, Ontario, Canada; and the ${ }^{\mathrm{b}}$ School of Epidemiology, Public Health, and Preventive Medicine, University of Ottawa, Ottawa, Ontario, Canada. Disclosures: Authors have nothing to disclose with regard to commercial support.

Received for publication Aug 9, 2015; revisions received Aug 9, 2015; accepted for publication Aug 10, 2015; available ahead of print Sept 5, 2015.

Address for reprints: Thierry G. Mesana, MD, PhD, University of Ottawa Heart Institute, 40 Ruskin St, Ottawa, Ontario, Canada K1Y 4W7 (E-mail: tmesana@ottawaheart.ca).

J Thorac Cardiovasc Surg 2015;150:1091-2

$0022-5223 / \$ 36.00$

Copyright (c) 2015 by The American Association for Thoracic Surgery

http://dx.doi.org/10.1016/j.jtcvs.2015.08.029
}

Mitral valve repair, as compared with replacement, is the criterion standard treatment for severe mitral regurgitation. $^{1-4}$ Favorable early and late results have been reported from expert mitral valve repair centers that use a range of repair techniques. ${ }^{1-4}$ Recent data, however, have shown that functional stenosis after repair may occur in patients who receive small complete annuloplasty rings. ${ }^{5,6}$

In their study in this issue of the Journal, Suh and colleagues ${ }^{7}$ compared annuloplasty ring types with respect to data derived from computed tomography (CT). ${ }^{7}$ This study was composed of 45 patients who underwent mitral valve repair during a 7-year period and subsequently underwent CT imaging for a variety of indications. Detailed measurements were subsequently made to determine the degree of mitral valve opening and the amount of pannus formation at a mean of 6.4 years after surgery. In addition to the small sample size, this study is limited by the nonrandomized nature of ring implantation. Patients in the study by Suh and colleagues $^{7}$ who received the Duran ring (Medtronic, Inc, Minneapolis, Minn) represented an older cohort relative to those who received the Carpentier-Edwards Classic ring (Edwards Lifesciences Corporation, Irvine, Calif); it therefore remains unclear whether the excess pannus formation in the Duran group may be attributed to the older age of the mitral valve reconstruction. Nevertheless, Suh and colleagues ${ }^{7}$ provide novel insights into the anatomy of functional mitral stenosis by correlating late pannus formation identified on CT with echocardiography. On the basis of these data, Suh and colleagues ${ }^{7}$ also sought to determine whether a difference exists in pannus formation between mitral annuloplasty types. Clearly the main determinant for late stenosis is the implantation of a small mitral annuloplasty ring, with subsequent pannus overgrowth gradually reducing the mitral valve orifice area over time.

One hypothesis explaining the excess pannus formation on the Duran ring may reside in the nonphysiologic circular reshaping of the mitral annulus away from the normal saddle shape. Mechanistically, late pannus formation is related surgery.

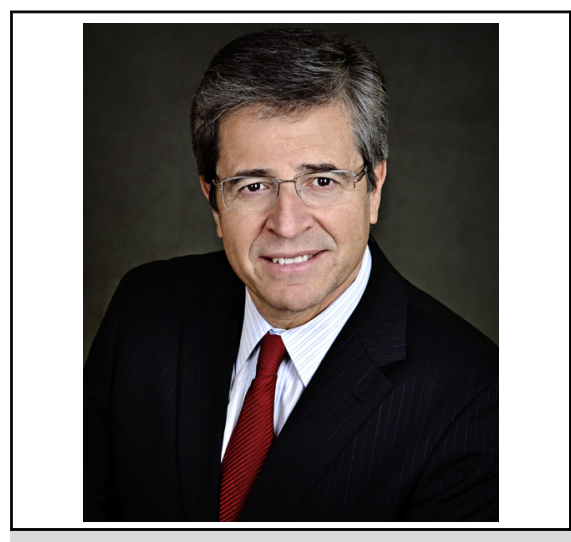

Thierry G. Mesana, MD, PhD

Central Message

Noninvasive cardiac imaging shows functional mitral stenosis to be a true anatomic problem created by imperfect surgical technique.

See Article page 1082 .

to disturbances in intraventricular flow patterns after annuloplasty, an effect that is more pronounced with small ring sizes. In a recent animal study, contrast magnetic resonance imaging was performed before and after mitral annuloplasty. ${ }^{8}$ This novel study confirms that changes in transmitral flow may occur after mitral valve repair and that the resulting turbulences above and below a reduced mitral orifice are precursors for late pannus formation.

Indeed, mitral annuloplasty is required for a successful and durable mitral valve repair. ${ }^{4}$ We should not forget, however, that all annuloplasty devices are rigid intracardiac structures and may be a source of late complications, similar to any prosthetic valve replacement. It seems quite logical that undersized or inadequately shaped annular devices are likely to result in anatomic problems early after

We previously found that functional mitral stenosis was more likely to occur after repair of degenerative mitral regurgitation in patients who received a complete mitral ring (Carpentier Physio Ring or Flexible Duran Ring), as opposed to a partial, semirigid band. In our study of 107 patients, ${ }^{6}$ individuals underwent stress echocardiography a mean of 4.3 years after mitral valve repair. Importantly, patients who received a complete ring had a higher mean mitral gradient and a higher right ventricular systolic 
pressure after repair. These echocardiographic differences were associated with adverse clinical events, including a higher incidence of atrial fibrillation. Similarly to the study by Suh and colleagues, ${ }^{7}$ we found a high degree of mitral stenosis after repair with the complete Duran rings, especially among individuals who received a ring smaller than $30 \mathrm{~mm}$. Consequently, we now avoid using complete annuloplasty rings for repairing degenerative mitral valves and instead favor partial bands to maintain the normal saddle shape of the annulus and the free motion of the anterior leaflet.

Postsurgical functional stenosis is an important consideration in the current era, because mitral valve repair is now commonly proposed for patients without symptoms. These patients are often young and active, and they accept mitral reconstruction for the long-term benefits of left ventricular function preservation and freedom from adverse events. ${ }^{1}$ Mitral valve reoperation for stenosis as a result of a small annuloplasty and pannus formation is complex, and a reoperative repair is not guaranteed. Typically, the surgeon will encounter a small mitral orifice with the mitral leaflets pushed down into the ventricle. All the tissues are fibrotic. The ring needs to be extracted after an extensive and circular débridement of all pannus formed above and below the ring to create a reasonable orifice. The posterior leaflet is short and thickened, and it therefore may require augmentation with either autologous or bovine pericardium.

The cohort of patients requiring reintervention for mitral stenosis after mitral valve repair is small, but these patients may represent only the "tip of the iceberg." The decision for reoperation must be made carefully. Most patients may tolerate for years significant transmitral gradients without symptoms at rest or with minimal exercise. Surveillance of functional mitral stenosis should focus on those individuals with elevated mean mitral gradients after repair and those patients who have received complete rings smaller than $30 \mathrm{~mm}$. Serial CT and echocardiographic imaging can be used for the better identification of anatomic problems created by additional pannus formation. These data may then be used to guide the surgeon toward a better decision regarding reintervention.

\section{References}

1. Chan V, Ruel M, Elmistekawy E, Mesana TG. Determinants of left ventricular dysfunction after repair of chronic asymptomatic mitral regurgitation. Ann Thorac Surg. 2015;99:38-42.

2. Castillo JG, Anyanwu AC, Fuster V, Adams DH. A near 100\% repair rate for mitral valve prolapse is achievable in a reference center: implications for future guidelines. J Thorac Cardiovasc Surg. 2012;144:308-12.

3. Carpentier A. Cardiac valve surgery-the "French correction." J Thorac Cardiovasc Surg. 1983;86:323-37.

4. Verma S, Mesana T. Mitral valve repair for mitral-valve prolapse. N Engl J Med. 2009;361:2261-9.

5. Fino C, Iacovoni A, Ferrero P, Senni M, Merlo M, Cugola D, et al. Restrictive mitral valve annuloplasty versus mitral valve replacement for functional ischemic mitral regurgitation: an exercise echocardiographic study. J Thorac Cardiovasc Surg. 2014;148:447-53.e2.

6. Mesana TG, Lam BK, Chan V, Chen K, Ruel M, Chan K. Clinical evaluation of functional mitral stenosis after mitral valve repair for degenerative disease: potential affect on surgical strategy. J Thorac Cardiovasc Surg. 2013;146:1418-23; discussion 1423-5.

7. Suh YJ, Chang BC, Im DJ, Kim YJ, Hong YU, Hong GR, et al. Assessment of mitral annuloplasty ring by cardiac CT: correlation with echocardiographic parameters and comparison between two different ring types. J Thorac Cardiovasc Surg. 2015;150:1082-90.

8. Witschey WR, Zhang D, Contijoch F, McGarvey JR, Lee M, Takebayashi S, et al. The influence of mitral annuloplasty on left ventricular flow dynamics. Ann Thorac Surg. 2015;100:114-21. 